\title{
FENOLOGIA DE CAGAITEIRA (Eugenia dysenterica DC.) NO ESTADO DE GOIÁS ${ }^{1}$
}

\author{
ELIREGINABARBOZA DE SOUZA ${ }^{2}$, RONALDO VELOSO NAVES ${ }^{2}$, JÁCOMO DIVINO BORGES ${ }^{2}$, ROSÂNGELA VERA $^{2}$, \\ ELIANA PAULA FERNANDES ${ }^{2}$, LUCIANA BORGES E SILVA ${ }^{3}$, MARIADA GLÓRIA TRINDADE ${ }^{4}$
}

RESUMO - O trabalho teve como objetivo avaliar o comportamento fenológico de cagaiteiras (Eugenia dysenterica DC.), nativas e cultivadas do cerrado de Goiás. As cagaiteiras cultivadas encontram-se implantadas na área experimental da Escola de Agronomia e Engenharia de Alimentos, da Universidade Federal de Goiás (EA/UFG), em Goiânia-GO, e a população nativa localizada no município de Senador Canedo-GO. Os dados climatológicos foram obtidos da Estação Evaporimétrica da EA/UFG. Foram estudadas as fenofases de folhação, floração e frutificação da cagaiteira no período de janeiro de 2004 a novembro de 2005. As cagaiteiras, nas duas condições (cultivadas e nativas), apresentaram o mesmo comportamento em relação às variáveis estudadas. Observou-se que a folhação das cagaiteiras ocorrem durante todo o ano e em intensidade no período de renovação das folhas, nos meses de setembro a outubro. Já o florescimento foi sincrônico e abundante. A frutificação foi menor em plantas mais novas, enquanto o desenvolvimento e a maturação dos frutos ocorrem entre 30 a 40 dias da antese das flores, coincidindo com o período chuvoso. As plantas mais velhas apresentam maior produção de cagaita nas duas épocas avaliadas.

Termos para indexação: cagaita, frutífera, cerrado, Myrtaceae.

\section{CAGAITEIRA (Eugenia dysenterica DC.) PHENOLOGY IN GOIÁS STATE}

ABSTRACT - The objective of this research was to accompany and to register the phenological behavior of the cagaiteira (Eugenia dysenterica DC.), relating the frequency of the phenophases in four $E$. dysenterica populations to the climate conditions of the studied period. Three of those populations are located at the Escola de Agronomia e Engenharia de Alimentos, Universidade Federal de Goiás (EA/UFG), in Goiânia, Goiás State (Brazil). A fourth population comprises native E. dysenterica plants, located in the municipality of Senador Canedo, Goiás State. Climatological data were obtained from the first class station at EA/UFG. The studied cagaiteira populations presented the same behavior of the appraised phenophases. The cagaiteira leafing in the studied populations behaves in a continuous way, during the whole year and at greater intensity in the period of total leaf renewal, coinciding with the increase of the relative air humidity and temperature in the months of September and October. The cagaiteira flowering is synchronic o and abundant. The fruiting was smaller in younger plants. The development and maturation of the fruit was fast (30 to 40 days) and coinciding with the start of the rainy season. Older and more developed cagaiteiras (Senador Canedo) presented higher production, some reaching over 2,000 fruits per year.

Index terms: Cerrado fruit tree, phenological patterns, Myrtaceae.

\section{INTRODUÇÃO}

Fenologia é o estudo das fases ou atividades do ciclo de vida dos vegetais e sua ocorrência temporal ao longo do ano, contribuindo para o entendimento dos padrões reprodutivos e vegetativos dos mesmos (Morellato, 1995).

Além das características intrínsecas das espécies, as variações climáticas também influenciam na fenologia, regulando a época, a intensidade, a duração e a periodicidade dos eventos fenológicos (Ferraz et al., 1999). Felfili et al. (1999) relatam que, no cerrado do Brasil Central, região de clima sazonal, com estações chuvosas e secas definidas, a pluviosidade tem sido apontada como condicionante da fenologia.

O desenvolvimento de pesquisas sobre os processos ecológicos envolvidos na reprodução de plantas do cerrado, segundo Freitas \& Oliveira (2002), é fundamental para melhor compreensão da diversidade estrutural e funcional desse bioma e, conseqüentemente, para o desenvolvimento de ferramentas úteis para sua conservação e manejo.

O conhecimento da fenologia das espécies do cerrado, de acordo com Araújo et al. (1987), é importante para o estabelecimento de critérios científicos que permitam melhor aproveitamento de suas potencialidades, especialmente na fruticultura e silvicultura, possibilitando, assim, prever épocas de crescimento vegetativo, floração, frutificação e dispersão de sementes. Esse conhecimento favorece, ainda, para estratégias de recuperação e manejo das áreas nativas com vegetação do cerrado.

Os primeiros estudos fenológicos sobre a cagaiteira (Eugenia dysenterica DC.) foram realizados por Sano et al. (1995).

\footnotetext{
(Trabalho 008-08). Recebido em: 02-01-2008. Aceito para publicação em: 04-11-2008. Parte da tese da primeira autora.

${ }^{2}$ Prof. Doutor em Agronomia-Produção Vegetal. Escola de Agronomia e Engenharia de Alimentos da Universidade Federal de Goiás - EA/UFG, CP 131, Rodovia Goiânia-Nova Veneza, km 0, 74001-970, Goiânia-GO. eliregina1@gmail.com; ronaldo@agro.ufg.br; jacomob@agro.ufg.br; vera@agro.ufg.br; elianafernandes@agro.ufg.br

${ }^{3}$ Eng $^{\mathrm{a}}$ Agr $^{\mathrm{a}}$, Dr $^{\mathrm{a}}$ em Agronomia-Produção Vegetal. lborges1001@yahoo.com.br

${ }^{4} \mathrm{Eng}^{\mathrm{a}} \mathrm{Agr}^{\mathrm{a}}$, M. Sc. em Agronomia-Melhoramento de Plantas. Ministério da Agricultura. trindade.mgloria@gmail.com
} 
No cerrado, existem espécies frutíferas nativas que apresentam potencial de cultivos em sistemas tradicionais, como a cagaiteira, da família Myrtaceae, uma árvore frutífera, com potencial ornamental e econômico, de porte médio, ocorrente na região dos cerrados (Almeida, 1998). Essa espécie apresenta crescimento lento, atingindo altura média de 5,00 metros aos 12 anos de idade (Souza, 2006).

A cagaiteira propagada por sementes inicia a frutificação a partir do quarto ou quinto ano de idade (Silva et al., 1992), sendo a média do início da formação dos frutos e maturação de, aproximadamente, quatro semanas. A maturação dos frutos é relativamente rápida e coincide com o início do período chuvoso. Esse fenômeno, provavelmente, pode estar relacionado à estratégia de estabelecimento da espécie, cujas sementes possuem uma viabilidade curta em condições naturais, menor que 50 dias (Farias Neto et al., 1991). Portanto, a sua dispersão logo no início do período chuvoso, parece ser imprescindível para que, após sua germinação, exista um período favorável de estabelecimento e crescimento para que a plântula possa sobreviver no período seco subseqüente (Sano et al., 1995).

O trabalho teve como objetivo avaliar o comportamento de cagaiteiras nativas e cultivadas no cerrado de Goiás.

\section{MATERIAL E MÉTODOS}

O trabalho com cagaiteiras (Eugenia dysenterica DC.) foi conduzido no período de janeiro de 2004 a novembro de 2005, na área experimental da Escola de Agronomia e Engenharia de Alimentos, da Universidade Federal de Goiás (EA/UFG), em Goiânia-GO, nas coordenadas geográficas $16^{\circ} 35^{\prime} 12^{\prime \prime}$ de latitude sul e 49 21'14" de longitude oeste a $730 \mathrm{~m}$ de altitude e na Fazenda Bom Sucesso, município de Senador Canedo-GO, a 16³7'18" de latitude sul, 4904'46" de longitude oeste a $892 \mathrm{~m}$ de altitude.

As cagaiteiras avaliadas foram caracterizadas em população A: arboreto composto por plantas de onze diferentes espécies frutíferas nativas do cerrado, incluindo a cagaiteira, na EA/UFG. Essa população de plantas foi implantada em fevereiro de 1993, com mudas obtidas a partir de sementes, tendo sido as plantas distribuídas em um modelo aleatório, sem espaçamento definido. De cada espécie, foram plantadas seis mudas por quadrante. Cada unidade assim constituída (quadrante) foi repetida quatro vezes (24 plantas de cada espécie, no total), totalizando 264 plantas, ocupando uma área útil total de $5.184 \mathrm{~m}^{2}$. Das 24 plantas de cagaiteira, foram selecionadas 10 ao acaso, das quais foram coletados os dados propostos nesta pesquisa. Já na população $B$, as cagaiteiras foram implantadas em maio de 1998 e conduzidas em espaçamento de $1,0 \mathrm{~m}$ x 0,80 m, composta por 225 plantas. Na população $\mathrm{C}$, as cagaiteiras pertenciam a uma coleção de germoplasma da EA/UFG, implantadas em janeiro de 1998, em espaçamento de 6,0 $\mathrm{m}$ x 6,0 m, constituindo 440 plantas, sendo provenientes de 110 plantasmães, estruturadas em 10 subpopulações oriundas da região sudeste de Goiás. O solo da área experimental da EA/UFG foi classificado como Latossolo Vermelho-Escuro. Foram avaliadas 209 e 406 plantas, respectivamente, nas populações B e C, de um total de 225 e 440, totalizando $93 \%$ de plantas que sobreviveram nessas populações após o plantio. População D: constituída por dez plantas adultas e de grande porte de cagaiteiras, de ocorrência natural, selecionadas na Fazenda Bom Sucesso, localizada no Município de Senador Canedo-GO. Essa população está sendo usada com pastagens, num solo classificado como Latossolo Vermelho-Escuro, distando das outras populações estudadas, em linha reta, aproximadamente $20 \mathrm{~km}$.

Os dados climatológicos da temperatura, precipitação, umidade relativa e insolação foram obtidos da Estação Evaporimétrica da EA/UFG. Para as populações A, B e C, foram utilizados dados climatológicos quinzenais, e para a população $\mathrm{D}$, dados mensais.

As caracterizações fenológicas foram realizadas no período de janeiro de 2004 a novembro de 2005, a intervalos quinzenais das populações A, B e C, e mensal da população D, determinando o percentual de folhas jovens, de coloração avermelhada, emitidas em cada novo lançamento, em relação ao total de folhas das copas. Também determinou-se o percentual entre flores e botões florais.

A metodologia empregada para folhação e floração foi de acordo com Ribeiro \& Castro (1986). O método possui intervalos de classes quando considerado $0=0 \%$ (ausência do fenômeno) $;=4 \% ; 2=15 \% ; 3=30 \% ; 4=50 \% ; 5=70 \% ; 6=85 \%$; $7=96 \%$ e $8=100 \%$. Para a frutificação, foram registradas as quantidades de frutos produzidos por planta nas condições de cultivo e nativas.

Foi calculada a média mensal dos eventos fenológicos observados em cada indivíduo considerado. Os dados das variáveis foram submetidos à análise de variância. As médias das variáveis foram comparadas pelo teste Tukey, a 5\% de probabilidade. Foram realizadas correlações de Pearson, com probabilidade de 5\%, entre os dados climatológicos e as fenofases, através do programa Genes (Cruz, 1997).

\section{RESULTADOS E DISCUSSÃO}

A folhação das cagaitas nas diferentes populações e as correlações significativas da fenofase em relação às temperaturas máxima e média, e à umidade relativa são indicadas como possíveis promotoras da emissão de folhas novas, contudo Wright \& Calderon (1995) reportam que os ritmos endógenos são fatores determinantes da emissão foliar.

Verifica-se que, na população A, a folhação correlacionou-se significativamente e positivamente com a temperatura máxima $(0,45)$ e a temperatura média $(0,32)$ (Figura 1$)$.

Nas populações B e C, as correlações significativas e positivas ocorreram entre folhação e temperatura máxima $(0,53$ e 0,62$)$, folhação e temperatura média $(0,45$ e 0,52$)$, e correlações significativas e negativas entre folhação e umidade relativa (0,32 e $-0,33$ ), respectivamente (Figuras 2 e 3 ).

Na população $\mathrm{D}$, houve correlação significativa e positiva entre folhação e temperatura máxima $(0,66)$, e correlação significativa e negativa entre folhação e umidade relativa $(-0,63)$ (Figura 4). 
As maiores precipitações ocorreram no período de outubro de 2003 a abril de 2004 e de outubro de 2004 a março de 2005. As menores precipitações ocorreram nos meses de maio a setembro de 2004 e de abril a setembro de 2005.

A emissão de folhas novas ocorreu ao longo do ano, com pico em setembro e outubro, nas populações de cagaiteiras, período de maior temperatura e menor umidade relativa.

De acordo com Sano et al. (1995), que estudaram as diferentes fenofases de cagaiteiras no cerrado de PlanaltinaDF, observou-se, visualmente, que o início da emissão de folhas novas nesta espécie foi anterior à queda total das folhas senescentes, e as plantas não ficaram totalmente desfolhadas. Verificaram, ainda, que a formação dos botões florais foi simultânea à emissão de folhas novas, e o período de floração coincidiu com o final da época seca e o início das chuvas. Essas observações estão de acordo com as obtidas no presente trabalho, pelo mesmo método.

Observou-se que o florescimento das cagaiteiras nas diferentes condições de cultivo foi simultâneo, porém a frutificação foi menor em plantas mais novas (Tabela 1), provavelmente, em função do menor volume de copa e do menor estabelecimento dessas plantas em relação ao crescimento radicular. Tal característica foi relatada por Poggiane (1973), quando citou ser a mesma muito importante, face à possibilidade de aproveitamento da água das camadas inferiores do solo.

Com relação à emissão de botões florais, somente na população B as correlações foram significativas e positivas nesta fenofase, com a umidade relativa $(0,99)$ e com a insolação $(0,99)$ (Figura 5).

Verificou-se ainda que não houve correlação significativa de florescimento em relação às condições climáticas, nas diferentes populações de cagaiteiras. A floração na primavera, período seco, parece ser o padrão seguido pela maioria das espécies da vegetação arbórea do Cerrado e de Savanas de latitudes próximas ao Equador (Sarmiento \& Monastério, 1983; Miranda, 1995). Em latitudes mais ao sul, como nos Cerrados do Planalto Central (Oliveira, 1998) e áreas disjuntas no sudeste (Batalha \& Mantovani, 2000), a floração na primavera coincide com o início das chuvas. Esse fato sugere que a floração na primavera independe do regime pluviométrico da região, e que a indução floral é decorrente de outros fatores.

Em levantamento em algumas espécies frutíferas em áreas de cerrado pouco antropizado, Naves (1999) constatou que a cagaiteira apresenta distribuição espacial em agregados. Proença \& Gibbs (1994) verificaram que essa espécie apresenta autofecundação, como fecundação cruzada, sendo a polinização realizada, principalmente, pelas mamangavas Bombus atratus e B. morio, pela manhã. Grandisoli (1997), estudando grandeuva (Psychotria suterella), observou distribuição espacial agregada para essa espécie, e considerou este padrão importante no aumento da atração visual e olfativa dos agentes polinizadores, principalmente para o gênero Bombus.

A cagaiteira propagada por sementes inicia a frutificação a partir do quarto ou quinto ano de idade (Silva et al., 1992), sendo a média do início da formação dos frutos e maturação de, aproximadamente, quatro semanas. A maturação dos frutos é relativamente rápida e coincide com o início do período chuvoso. Esse fenômeno, provavelmente, pode estar relacionado à estratégia de estabelecimento da espécie, cujas sementes possuem uma viabilidade curta em condições naturais, menor que 50 dias (Farias Neto et al., 1991). Portanto, a sua dispersão logo no início do período chuvoso parece ser imprescindível para que, após sua germinação, exista um período favorável de estabelecimento e crescimento para que a plântula possa sobreviver no período seco subseqüente (Sano et al., 1995). A fenologia da frutificação da cagaiteira, conforme observada por outros autores, apresenta um padrão similar ao encontrado neste estudo.

Verificou-se, para a cagaiteira, que não houve correlação significativa entre a frutificação e os parâmetros climáticos considerados.

O percentual de frutificação na população A de cagaiteiras conduzidas na EA/UFG foi de 60\% em 2004 e 80\% em 2005. Enquanto na população B, o percentual médio foi de $30,14 \%$ e $35,41 \%$, em 2004 e 2005, respectivamente. Na população C, foi de $5,91 \%$, em 2004, e 21,18\%, em 2005. Já na população D, o percentual de frutificação foi de $100 \%$ (Tabela 1).

Em relação ao parâmetro produção, observou-se que, na população $\mathrm{A}$, houve incremento de $36,84 \%$ de frutos, enquanto a população B, mesmo com a menor produção em 2005 , apresentou maior número de plantas produzindo. Nas populações $\mathrm{C}$ e $\mathrm{D}$, o incremento de produção foi de $61,54 \%$ e $13,70 \%$, respectivamente (Tabela 1). A população D, avaliada no município de Senador Canedo-GO, apresentou produção maior em relação às demais populações por constituir-se de plantas adultas. Durante o período do estudo, possivelmente as cagaiteiras apresentaram pequena alternância de produção.

A quantidade de frutos produzidos em cagaiteiras é irregular. Assim, Rizzini (1970) observou, em 1967, na região de Paraopeba-MG, grande safra de cagaita com frutos maduros em meados de outubro; enquanto, em 1968, a produção foi pequena, com maturação de frutos em novembro. Em 1969, a frutificação foi idêntica à de 1967.

Tal comportamento pode ser esclarecido pelo relatado por Newstrom et al. (1994), que a floração e a frutificação são dependentes do ambiente onde se desenvolvem as plantas, além da espécie e de seu estádio de desenvolvimento. 
TABELA 1- Dados médios do número total de plantas (NTP), plantas que floresceram (PF), plantas que produziram frutos (PP) e número médio de frutos produzidos por planta $\left(\mathrm{N}^{\circ} \mathrm{F}\right)$, nas populações de cagaiteiras (Eugenia dysenterica), em 2004 e 2005.

\begin{tabular}{lrrrr|rrr}
\hline \multirow{2}{*}{ Populações $^{1}$} & NTP & \multicolumn{2}{c|}{2004} & \multicolumn{2}{c}{2005} \\
\cline { 3 - 7 } & & PF & PP & $N^{\circ} \mathrm{F}$ & PF & PP & $\mathrm{N}^{\circ} \mathrm{F}$ \\
População A & 10 & 10 & 6 & 19 & 10 & 8 & 26 \\
População B & 209 & 65 & 63 & 28 & 85 & 74 & 19 \\
População C & 406 & 37 & 24 & 13 & 160 & 86 & 21 \\
População D & 10 & 10 & 10 & 2.700 & 10 & 10 & 3.070 \\
\hline
\end{tabular}

Populações A - arboreto da Escola de Agronomia e Engenharia de Alimentos da Universidade Federal de Goiás (EA/UFG); B e C (EA/UFG), município de Goiânia-GO; D - natural (Município de Senador Canedo-GO).

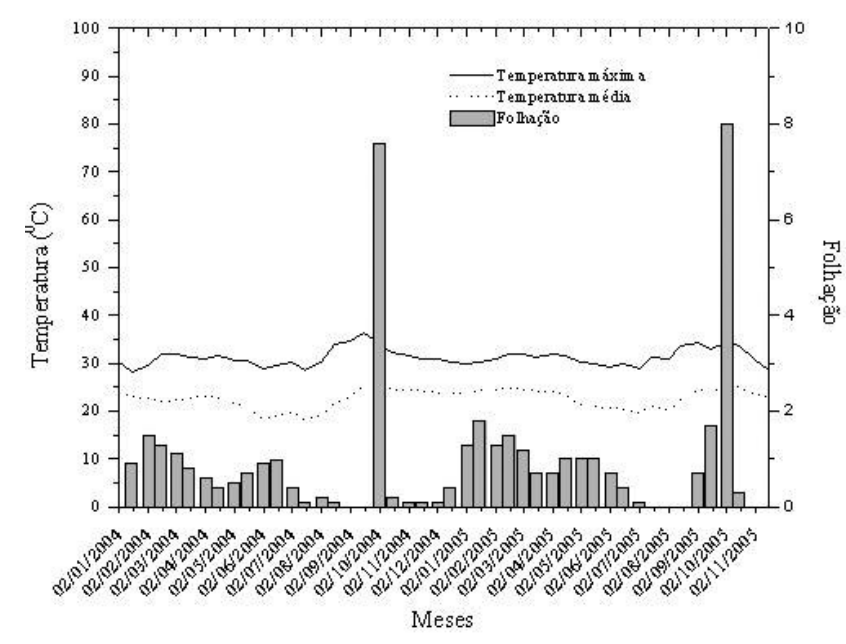

FIGURA 1- Temperaturas máxima e média quinzenais e folhação da população A de cagaiteiras (Eugenia dysenterica), referentes aos meses de janeiro de 2004 a novembro de 2005, na Escola de Agronomia e Engenharia de Alimentos da Universidade Federal de Goiás. Goiânia-GO.

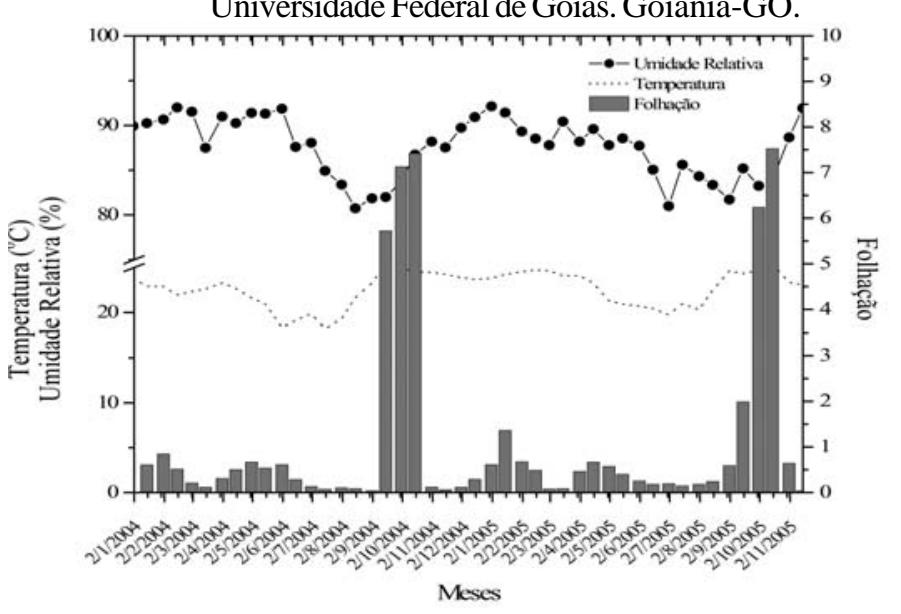

FIGURA 2- Temperaturas máxima e média, e umidade relativa quinzenais e folhação da população B de cagaiteiras (Eugenia dysenterica), referentes aos meses de janeiro de 2004 a novembro de 2005, na Escola de Agronomia e Engenharia de Alimentos da Universidade Federal de Goiás. Goiânia-GO.

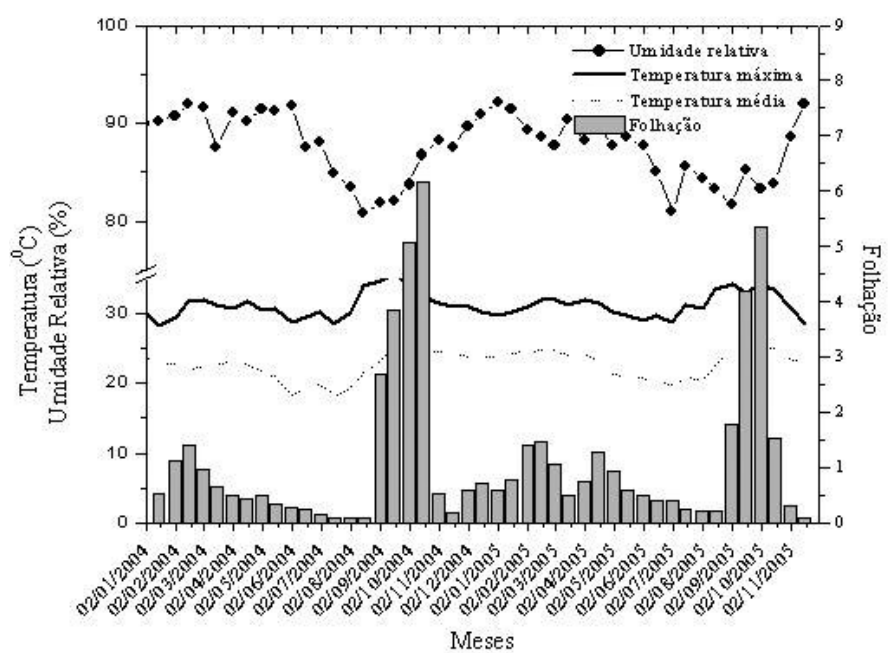

FIGURA 3- Temperaturas máxima e média e umidade relativa quinzenais e folhação da população $\mathrm{C}$ de cagaiteiras (Eugenia dysenterica), referentes aos meses de janeiro de 2004 a novembro de 2005, na Escola de Agronomia e Engenharia de Alimentos da Universidade Federal de Goiás. Goiânia-GO.

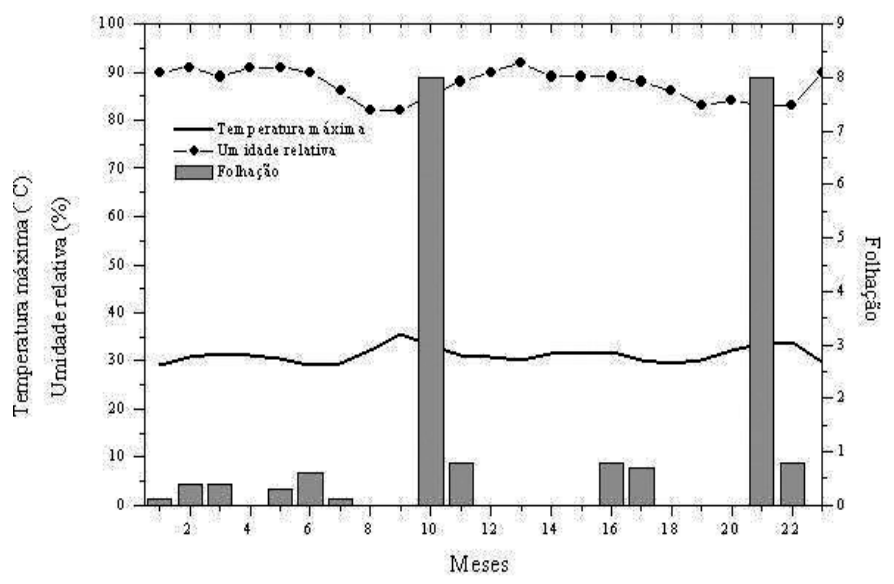

FIGURA4- Temperatura máxima e umidade relativa mensal e folhação da população D de cagaiteiras (Eugenia dysenterica), referentes aos meses de janeiro de 2004 a novembro de 2005, no município de Senador Canedo-GO. 


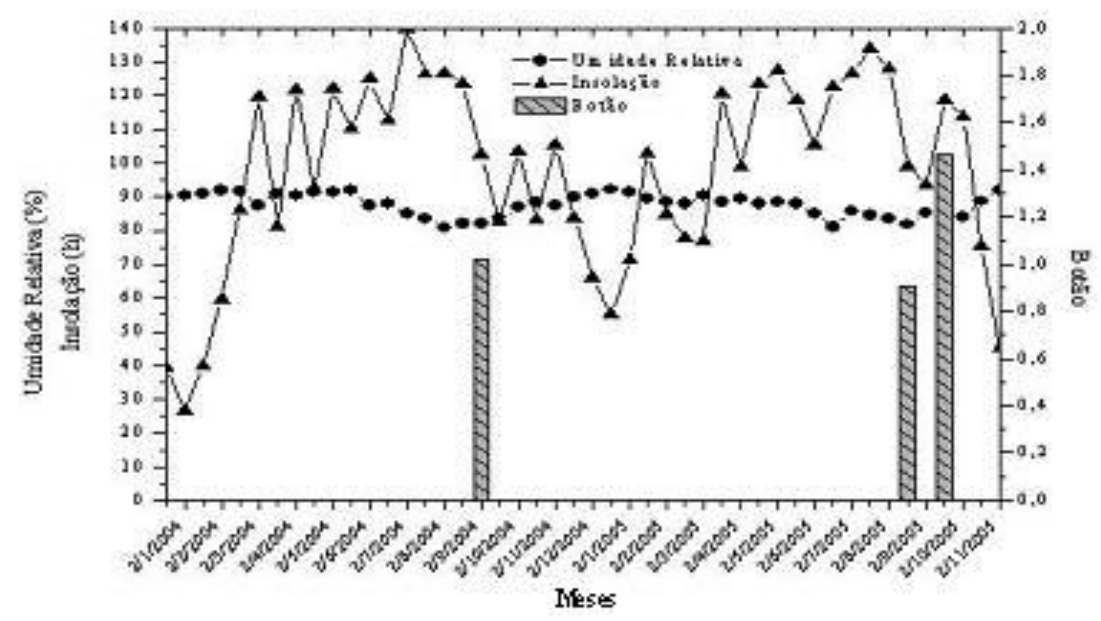

FIGURA 5- Umidade relativa e insolação quinzenais e botão floral da população B de cagaiteiras (Eugenia dysenterica), referentes aos meses de janeiro de 2004 a novembro de 2005, na Escola de Agronomia e Engenharia de Alimentos da Universidade Federal de Goiás. Goiânia-GO.

\section{CONCLUSÕES}

1-As cagaiteiras apresentam comportamentos semelhantes em relação à folhação, florescimento e frutificação, tanto nas condições de cultivo quanto no meio natural.

2-A folhação das cagaiteiras ocorre durante todo o ano, com maior intensidade no período de renovação total das folhas, coincidindo com a umidade relativa do ar e a temperatura altas.

3-O florescimento das cagaiteiras é sincrônico e com menor frutificação em plantas novas.

4-O desenvolvimento e a maturação dos frutos ocorrem entre 30 e 40 dias após a antese das flores, coincidindo com o período chuvoso.

5-As cagaiteiras mais velhas e maiores apresentam maior produção.

\section{REFERÊNCIAS}

ALMEIDA, S. P. Frutas nativas do cerrado: caracterização físicoquímica e fonte potencial de nutrientes. In: SANO, S. M.; ALMEIDA, S. P. (Ed.). Cerrado: ambiente e flora. Planaltina: Embrapa-CPAC, 1998. p. 247-285.

ARAÚJO, G. M.; FRANCISCON, C. H.; NUNES, J. G. Fenologia de nove espécies arbóreas de um cerrado no município de Uberlândia-MG. Revista do Centro de Ciências Biomédicas da Universidade Federal de Uberlândia, Uberlândia, v. 3, n. 1, p. 317, 1987.

BATALHA, M. A.; MANTOVANI, W. Reproductive phenological patterns of cerrado plant species at the Pé-deGigante Reserve (Santa Rita do Passa Quatro, SP, Brazil): comparison between the herbaceous and woody floras. Revista Brasileira de Biologia, Rio de Janeiro, v.60, p. 129-145, 2000.
CRUZ, C. D. Programa GENES: aplicativo computacional em genética e estatística. Viçosa: UFV, 1997. 442 p.

FARIAS NETO,A.L.; FONSECA,C.E.L.; GOMIDE,C.C.C.; SILVA, J. A. Armazenamento de sementes de cagaita (Eugenia dysenterica DC). Revista Brasileira de Fruticultura, Jaboticabal, v. 13, n. 2, p. 55-62, 1991.

FELFILI, J. M.; SILVAJÚNIOR, M.C. da; DIAS, B. J.; REZENDE, A. V. Estudo fenológico de Stryphnodendron adstringens (Mart.) Coville no cerrado sensu stricto da Fazenda Água Limpa no Distrito Federal, Brasil. Revista Brasileira de Botânica, São Paulo, v. 22, n. 1, p. 83-90, 1999.

FERRAZ, D. K.; ARTES, R.; MANTOVANI, W.; MAGALHÃES, L. M. Fenologia de árvores em fragmento de mata em São PauloSP. Revista Brasileira de Biologia, Rio de Janeiro, v. 59, n. 2, p. 305-317, 1999.

FREITAS, C. V.; OLIVEIRA, P. E. Biologia reprodutiva de Copaifera langsdorffii Desf. (Leguminosae, Caesalpinioideae). Revista Brasileira de Botânica, São Paulo, v. 25, n. 3, p. 311-321, set. 2002

GRANDISOLI, E. A. C. Biologia reprodutiva e estrutura da população de Psychotria suterella Muell. Arg. (Rubiaceae) em um fragmento de mata secundária em São Paulo (SP). 1997. 84 f. Dissertação (Mestrado) - Instituto de Biociências, Universidade de São Paulo, São Paulo, 1997.

MIRANDA, I. S. Fenologia do estrato arbóreo de uma comunidade de cerrado em Alter-do-Chão, Pará. Revista Brasileira de Botânica, São Paulo, v.18, p. 235-240, 1995.

MORELLATO, L. P. C. As estações do ano na floresta. In: LEITÃO FILHO, H. F.; MORELLATO, L. P.C. (Org.). Ecologia e preservação 
de uma floresta tropical urbana: Reserva de Santa Genebra. Campinas: UNICAMP, 1995. p. 187-192.

NAVES, R.V. Espécies frutíferas nativas dos cerrados de Goiás: caracterização e influências do clima e dos solos. 1999. 206 f. Tese (Doutorado em Agronomia: Produção Vegetal) - Escola de Agronomia, Universidade Federal de Goiás, Goiânia, 1999.

NEWSTROM,L.E.; FRANKIE, G. W.; BAKER, H. G; COLWELL, R. K. Diversity of long-term flowering patterns. In: MCDADE, L.A.; BAWA, K. S.; HESPENHEIDE, H. A.; HARSTSHORN, G. S. (Eds.). La selva: ecology and natural history of a neotropical rain forest. Chicago: University Chicago, 1994. p.142-160.

OLIVEIRA, P. O. Fenologia e biologia reprodutiva das espécies de cerrado. In: SANO, S. M.; ALMEIDA, S. P. (Ed.). Cerrado: ambiente e flora. Planaltina: Embrapa-CPAC, 1998. p. 169-192.

POGGIANE, F. Aspectos do crescimento e do metabolismo auxínico de plântulas de espécies do cerrado. 1973. 153 f. Tese (Doutorado em Ciências) - Escola Superior de Agricultura Luiz de Queiroz, Universidade de São Paulo, São Paulo, 1973.

PROENÇA, C.E.B.; GIBBS, P.E. Reproductive biology of eight sumpatric Myrtaceae from Central Brazil. New Phytologist, Oxford, v.126, p.343-354, 1994.

RIBEIRO, J.F.; CASTRO, L.H.R. Método quantitativo para avaliar características fenológicas em árvores. Revista Brasileira de Botânica, São Paulo, v. 9, n.1, p.7-11, jul. 1986.
RIZZINI, C. T. Efeito tegumentar na germinação de Eugenia dysenterica DC. (Myrtaceae). Revista Brasileira de Biologia, Rio de Janeiro, v. 30, n. 3, p. 381-402. 1970.

SANO, S. M.; FONSECA, C. E. L. da; RIBEIRO, J. F.; OGA, F. M.; LUIZ, A. J. B. Folhação, floração, frutificação e crescimento inicial da cagaiteira em Planaltina-DF. Pesquisa Agropecuária Brasileira, Brasília, v. 30, n. 1, p. 5-14, jan. 1995.

SARMIENTO, G.; MONASTERIO, M. Life forms and phenology. In: BOURLIÈRE, F. (Ed.). Ecosystems of the word: tropical savannas. Amsterdan: Elsevier Science, 1983. p. 79-108.

SILVA, J. A.; SILVA, D. B.; JUNQUEIRA, N. T. V.; ANDRADE, L. R. M. de. Coleta de sementes, produção de mudas e plantio de espécies frutíferas nativas dos cerrados: informações exploratórias. Planaltina: EMBRAPA/CPAC, 1992. 23 p. (Documentos, 44).

SOUZA, E. R. B. de. Fenologia, dados biométricos, nutrição de plantas e qualidade de frutos de cagaiteira (Eugenia dysenterica DC.) no Estado de Goiás. 2006. 114 f. Tese (Doutorado em Agronomia) - Escola de Agronomia e Engenharia de Alimentos, Universidade Federal de Goiás, Goiânia, 2006.

WRIGHT, S. J.; CALDERON, O. Phylogenetic patterns among tropical flowering phenologies. Journal of Ecology, Oxford, v.83, p. 937-948. 1995. 